\title{
A Step Forward: From Conceptualizing to Measuring Successful Aging at Work
}

\author{
STANIMIRA K. TANEVA \\ Faculty of Social Sciences, University of Nottingham, UK
}

GEORGI P. YANKOV

Development Dimensions International, USA

Correspondence to Stanimira Taneva, University of Nottingham, Room B42, Law \& Social Sciences Building, University Park, Nottingham, NG7 2RD, United Kingdom, Phone: +44 (0) 115 9587126, Email: Stanimira.Taneva@nottingham.ac.uk

Please Cite As:

Taneva, S. K. \& Yankov, G. P. (2020). A Step Forward: From Conceptualizing to Measuring Successful Aging at Work. Industrial and Organizational Psychology: Perspectives on Science and Practice. [In Press Accepted Manuscript]. 


\section{A Step Forward: From Conceptualizing to Measuring Successful Aging at Work}

Up-to-date, the emerging construct Successful Aging at Work (SAW) has been conceptualized as the sustainable maintenance of one's health, motivation, and ability to work (cf. Kooij et al., 2015) or an age-related intra-individual trajectory of growth (i.e., a trajectory that deviates positively from the average age-related trajectory) of a specific work outcome (e.g., job performance or work well-being) (cf. Zacher, 2015). Kooij, Zacher, Wang, and Heckhausen (2020) proposed a practical definition, in which SAW is described as “...the proactive maintenance of, or adaptive recovery (after decline) to, high levels of ability and motivation to continue working among older workers" (p.14). Moreover, this maintenance process is viewed as driven by older workers' self-regulation behaviors aimed at maintaining, adjusting or restoring the person-environment (P-E) fit and shaped by various multi-level factors (e.g., personal, job, organizational, and wider societal) (Kooij et al., 2020).

We complement Kooij et al.’s (2020) practical conceptualization of SAW by asserting that SAW may not be limited to maintaining or restoring older workers' levels of ability/motivation, for two main reasons. First, for many (older) workers SAW may be experienced as age-related growth (cf. Zacker, 2015; Taneva, Arnold, \& Nicolson, 2016) rather than adaptive maintenance and/or recovery. Second, SAW may be experienced by workers at various ages/career stages (cf. Zacher, Kooij, \& Beier, 2018), and, therefore, is not associated with older workers only. To substantiate these propositions, we went beyond the theoretical conceptualization of SAW by developing a new measurement instrument of SAW (Taneva \& Yankov, 2020). Consequently, we tested the relationships of SAW with a variety of personal and contextual variables (cf. Kooij et al., 2020; Zacher, 2015) in two studies, in 2018 and 2020, with overall 544 workers based in the United States (US). The results supported the growth aspect and the career-wide manifestations of SAW. Also, we found that, 
when interpreted in growth (vs maintenance) terms, the construct SAW fits within the overall conceptual framework and process model proposed by Kooij et al. (2020). We conclude our commentary by suggesting recommendations for academic and professional practice.

\section{Emphasizing the Growth Dimension}

SAW may be viewed from a wider perspective than Kooij et al.'s (2020). In their influential article "Aging, Adult Development, and Work Motivation” Kanfer and Ackerman (2004) noted that, while in the US aging is often associated with general decline (e.g., in cognitive abilities), such “... assumption of general decline with age is simplistic and misleading”, because “...adult development is not simply a matter of decline but can better be considered in terms of four distinct patterns of development, namely, loss, growth, reorganization, and exchange [of resources]" (p. 442). Since then, researchers have focused on these patterns of adult development to a varied extent - some emphasizing the prevention of developmental losses (e.g., declining cognitive abilities), others capitalizing on the developmental gains (e.g., increased knowledge) (cf. Ebner, Freund, \& Baltes, 2006; Kooij, Lange, Jansen, Kanfer, \& Dikkers, 2011; Taneva et al., 2016). This is also reflected in the recently proposed lifespan definitions of the construct SAW (Kooij, 2015; Zacher, 2015; Zacher et al., 2018; Kooij et al., 2020).

In line with Zacher's theoretical definition of SAW as an age-related intra-individual trajectory of growth (Zacher, 2015), in 2018 we operationalized the construct SAW and developed a new measurement instrument - a SAW scale (cf. Taneva \& Yankov, 2020). Our measure addresses the need to explore the subjective meanings of SAW for older workers (cf. Olson, \& Shultz, 2019) by building upon the outcomes of previous qualitative studies with older workers (cf. Taneva et al., 2016; Taneva \& Arnold, 2018). For example, in the Taneva et al.'s (2016) study, most of the interviewed older workers (aged 55 years and older) shared positive experiences in the workplace, associating older age with increased knowledge and 
experience, self-awareness and confidence; improved social skills, emotion regulation, ability to solve complex problems, and general adaptation to contextual changes. Furthermore, older workers' perceptions of intra-individual growth appeared positively associated with the workers' conceptualizations of what a supportive work environment would look like.

\section{Testing the Relationships between SAW and Other Constructs}

In support of our claims in this commentary that SAW (i) can be captured through its growth dimension and (ii) may be experienced throughout the overall working lifecycle, in the below paragraphs we present empirical results from two studies. A summary of the results is depicted on Figure 1.

In 2018, we conducted a series of analyses with a sample of 417 MTurk workers in the US to explore the relationships between the SAW scale and established measures for employees' self-regulation behaviors, job characteristics, organizational Human Resource Management (HRM) practices, employees' organizational tenure and chronological age (cf. Taneva \& Yankov, 2020). This is in line with Kooij et al.'s (2020) framework of facilitating factors and model of SAW. In addition, we investigated the associations of SAW with two types of individual-level work outcomes - work ability and well-being (cf. Taneva \& Yankov, 2020).

Given the prominent role of P-E fit in Kooij et al.'s (2020) process model, in 2020 we conducted an additional study with a sample of 127 US workers, using the participant pool platform Prolific ${ }^{1}$. The mean age for the sample was $49.2(\mathrm{SD}=14,5)$, with $41 \%$ of the

1 Prolific is an emerging alternative to Amazon MTurk for conducting remote studies with participants online. Besides Prolific's fairer paying practices to its participants, there is also evidence that Prolific participants are more attentive than MTurk's (Palan \& Schitter, 2018). 
participants aged 60 years and over. In this study, the SAW scale was tested regarding three measures of self-perceived P-E fit, employees' job level, chronological and subjective age.

The conceptual framework and process model of SAW. In 2018 (cf. Taneva \& Yankov, 2020), we found strong support of the predicted relationships of SAW with the use of self-regulation (selection, optimization, and compensation; cf. Freund \& Baltes, 2002) strategies, five job characteristics (autonomy, task significance, skill variety, social support, feedback from others; cf. Morgeson \& Humphrey, 2006), work ability (cf. Tuomi, Ilmarinen, Jahkola, Katajarinne, \& Tulkki, 1998), and thriving at work (Porath, Spreitzer, Gibson, \& Garnett, 2012) as a form of psychological well-being. However, we did not find statistically significant relationships of SAW with employees' experiences of surviving at work (cf. Taneva \& Arnold, 2018) - another form of psychological well-being, emphasizing the employees' approach to maintaining or preserving, as opposed to developing their resources.

In the 2020 study, the SAW score significantly related to job level $(r=.20 ; p<.05)$, indicating that employees in white-collar jobs are more likely to experience SAW (viewed as intra-individual growth throughout the working lifecycle) than those in blue-collar jobs. This may be because white-collar jobs involve job characteristics (such as, e.g., a higher level of autonomy) that allow the use of SAW-facilitating strategies (e.g., self-regulation behaviors) more than blue-collar jobs. Taken together, the reported above findings from the two studies support the growth aspect of SAW and the associations of SAW with key constructs from the Kooij et al.'s (2020) conceptual framework.

With regard to the anticipated associations of SAW with P-E environment fit, the SAW scale was tested against three measures of self-perceived P-E fit (Person-Organization Fit [POFS], Person-Job Fit [PJFS], and Person-Supervisor Fit [PSFS]; cf. Chuang, Shen, and Judge, 2016). We found strong positive relationships between the SAW and all P-E fit scores (for POFS $r=.70$, PJFS $r=.55$, and PSFS $=.68$, with $\mathrm{p}<0.01$ for all). Importantly, we 
established that the three P-E scores significantly $(\mathrm{p}<.0001)$ predicted the total SAW score. The beta coefficients of the three scales were almost equal, ranging from .29 (PJFS) to .35 (POFS). When all scales were put into the regression equation to predict SAW, only POFS and PSFS were significant $(\mathrm{p}<.0001)$ predictors, with beta coefficients of .19 and .15 respectively. These findings support the proposed general associations between SAW and PE fit in Kooij et al.'s (2020) model.

Employees' age and experiences of $S A W$. Although some authors suggested that SAW can be experienced throughout the overall working cycle (cf. Zacher et al., 2018), up-to-date research in this field has focused mostly on older workers (cf. Olson \& Shultz, 2019). The relevance of SAW for, specifically, older workers is also highlighted in Kooij et al.'s (2020) practical definition.

In our two studies $(2018 ; 2020)$, we tested the potential associations between workers' age and experiences of SAW in several ways. First, we considered employees' chronological age (cf. Kooij, De Lange, Jansen, \& Dikkers, 2008). We did not find statistically significant relationships of SAW with employees' chronological age neither in 2018 (as reported in Taneva \& Yankov, 2020), nor in 2020 (where $r=.12$, ns). Second, in 2018 we tested the potential associations between SAW and workers' organizational tenure, which may also be interpreted as workers' organizational age (cf. Kooij et al., 2008). We did not find a significant relationship (cf. Taneva \& Yankov, 2020). Third, in 2020 we followed Rudolph, Kunze, and Zacher's (2019) advice that “...This extension [subjective age] has... the potential to tell us more about the consequences of the aging processes at the workplace than chronological age alone" (p. 10) and explored the potential relationship of SAW with workers' subjective age. No significant association $(\mathrm{r}=.08, \mathrm{~ns})$ was found.

One potential explanation of the lack of significant correlations of SAW with age in our studies may be that, at least when defined in growth terms, SAW may be experienced at all 
career stages, and not just by older workers per se, as suggested in Kooij et al.'s (2020) practical definition.

\section{Concluding Remarks}

In the present commentary, we propose a complementary description of SAW with an emphasis on the growth dimension of this multi-faceted construct. Based on this description, we operationalized and measured the construct SAW in a series of empirical studies conducted in 2018 and 2020. The results revealed that, when operationalized in terms of the employees' self-perceptions of age-related intra-individual growth (vs maintenance or recovery), the construct SAW fits within the overall conceptual framework and process model proposed by Kooij and colleagues (2020). Moreover, we demonstrated that, when viewed as a growth process, SAW may be experienced throughout the whole working cycle and, therefore, may not be associated with older workers only.

We suggest that researchers consider our measurement approach to SAW for their studies of SAW. We realize that successful operationalizations of SAW depend on exploring the prototypical behaviors of successfully aging individuals. These (self-regulation) behaviors, associated with maintaining, adjusting and restoring P-E fit, should correspond to the interactions between various multi-level factors, which Kooij and colleagues (2020) refer to in their article. From a practitioner perspective, the measurement of SAW may support the organizational training and development agendas by helping to capture (hence, utilize) employees' potential to age successfully in the workplace. From an employee perspective, the measurement of SAW may help workers in monitoring and enhancing their own experiences of SAW. Ensuring SAW from both individual and organizational angles may ultimately help to sustain longer and healthier working lives. 


\section{References}

Baltes, P. B., \& Baltes, M. M. (1990). Psychological perspectives on successful aging: The model of selective optimization with compensation. In P. B. Baltes \& M. M. Baltes. (Eds.), Successful aging: Perspectives from the behavioral sciences (pp. 1-34). New York,NY: Cambridge University Press. doi:10.1017/CBO9780511665684.003

Chuang, A., Shen, C., \& Judge, T.A. (2019). Development of a Multidimensional Instrument of Person-Environment Fit: The Perceived Person-Environment Fit Scale (PPEES). Applied Psychology: An International Review, 65 (1), 66-98. doi: 10.1111/apps.12036

Ebner, N. C., Freund, A. M., \& Baltes, P. B. (2006). Developmental changes in personal goal orientation from young to late adulthood: From striving for gains to maintenance and prevention of losses. Psychology and Aging, 21, 664-678. doi:10.1037/08827974.21.4.664

Freund, A. M. \& Baltes, P. B. (2002). Life-management strategies of selection, optimization and compensation: Measurement by self-report and construct validity. Journal of Personality and Social Psychology, 82(4), 642-662. doi:10.1037/0022-3514.82.4.642

Kanfer, R. \& Ackerman, P. L. (2004). Aging, adult development, and work motivation. Academy of Management Review, 29(3), 440-458. doi:10.2307/20159053

Kooij, D., Zacher, H., Wang, M., \& Heckhausen, J. (2020). Successful Aging at Work: A Process Model to Guide Future Research and Practice. Industrial and Organizational Psychology, 13(3), 1-55. doi:10.1017/iop.2020.1

Kooij, D. T. A. M. (2015). Successful aging at work: The active role of employees. Work, Aging and Retirement, 1(4), 309-319. doi:10.1093/workar/wav018

Kooij, D. T. A. M., De Lange, A. H., Jansen, P. G. W., Kanfer, R., \& Dikkers, J. S. E. (2011). Age and work-related motives: Results of a meta-analysis. Journal of Organizational Behavior, 32(2), 197-225. doi:10.1002/job.665 
Kooij, D., De Lange, A., Jansen, P., \& Dikkers, J. (2008). Older Workers' Motivation to Continue to Work: Five Meanings of Age: A Conceptual Review. Journal of Managerial Psychology, 23 (4), 364-394. doi: 10.1108/02683940810869015

Morgeson, F. P., \& Humphrey, S. E. (2006). The Work Design Questionnaire (WDQ): Developing and validating a comprehensive measure for assessing job design and the nature of work. Journal of Applied Psychology, 91, 1321-1339. doi:10.1037/00219010.91.6.1321

Olson, D. \& Shultz, K. (2019). Lifespan Perspectives on Successful Aging at Work. In B. B. Baltes, C. W. Rudolph, \& H. Zacher (Eds.), Work Across the Lifespan (pp. 215 - 234). Academic Press, Elsevier. eBook ISBN: 9780128127575

Palan, S. \& Schitter, C. (2018). Prolific. ac_-A subject pool for online experiments. Journal of Behavioral and Experimental Finance, 17, 22-27. doi: 10.1016/j.jbef.2017.12.004

Porath, C., Spreitzer, G., Gibson, C., \& Garnett, F. G. (2012). Thriving at work: Toward its measurement, construct validation, and theoretical refinement. Journal of Organizational Behavior, 33(2), 250-275. doi:10.1002/job.756

Rudolph, C. W., Kunze, F., \& Zacher, H. (2019). Getting Objective About Subjective Age: Introduction to a Special Issue. Work, Aging and Retirement, 5(4), 265272.doi:10.1093/workar/waz019

Stephan, Y., Demulier, V., \& Terracciano, A. (2012). Personality, Self-Rated Health and Subjective Age in a Life-Span Sample: The Moderating Role of Chronological Age. Psychological Aging, 27(4), 875-880. doi:10.1037/a0028301

Taneva, S. K. \& Yankov, G. P. (2020). A New Perspective to Measuring Employee Growth: Developing a Successful Aging at Work Scale. Personnel Assessment and Decisions, 6(1), 48-62, doi: 10.25035/pad.2020.01.005 
Taneva, S. K., \& Arnold, J. (2018). Thriving, Surviving and Performing in Late Career: A Mixed-Method Study of Pathways to Successful Aging in Organizations. Work, Aging and Retirement, 4 (2), 189-212. doi:10.1093/workar/wax027

Taneva, S. K., Arnold, J., \& Nicolson, R. (2016). The experience of being an older worker in an organization: a qualitative analysis. Work, Aging and Retirement, 2(4), 396-414. doi: 10.1093/workar/waw011

Tuomi, K., Ilmarinen, J., Jahkola, A., Katajarinne, L., \& Tulkki, A. (1998). Work Ability Index 2nd Edition. Helsinki: Institute of Occupational Health.

Zacher, H. (2015). Successful aging at work. Work, Aging and Retirement, 1(1), 4-25. doi: 10.1093/workar/way002

Zacher, H., Kooij, D. T.A.M., \& Beier, M. E. (2018). Active aging at work: Contributing factors and implications for organizations. Organizational Dynamics, 47(1), 37-45. doi:10.1016/j.orgdyn.2017.08.001 


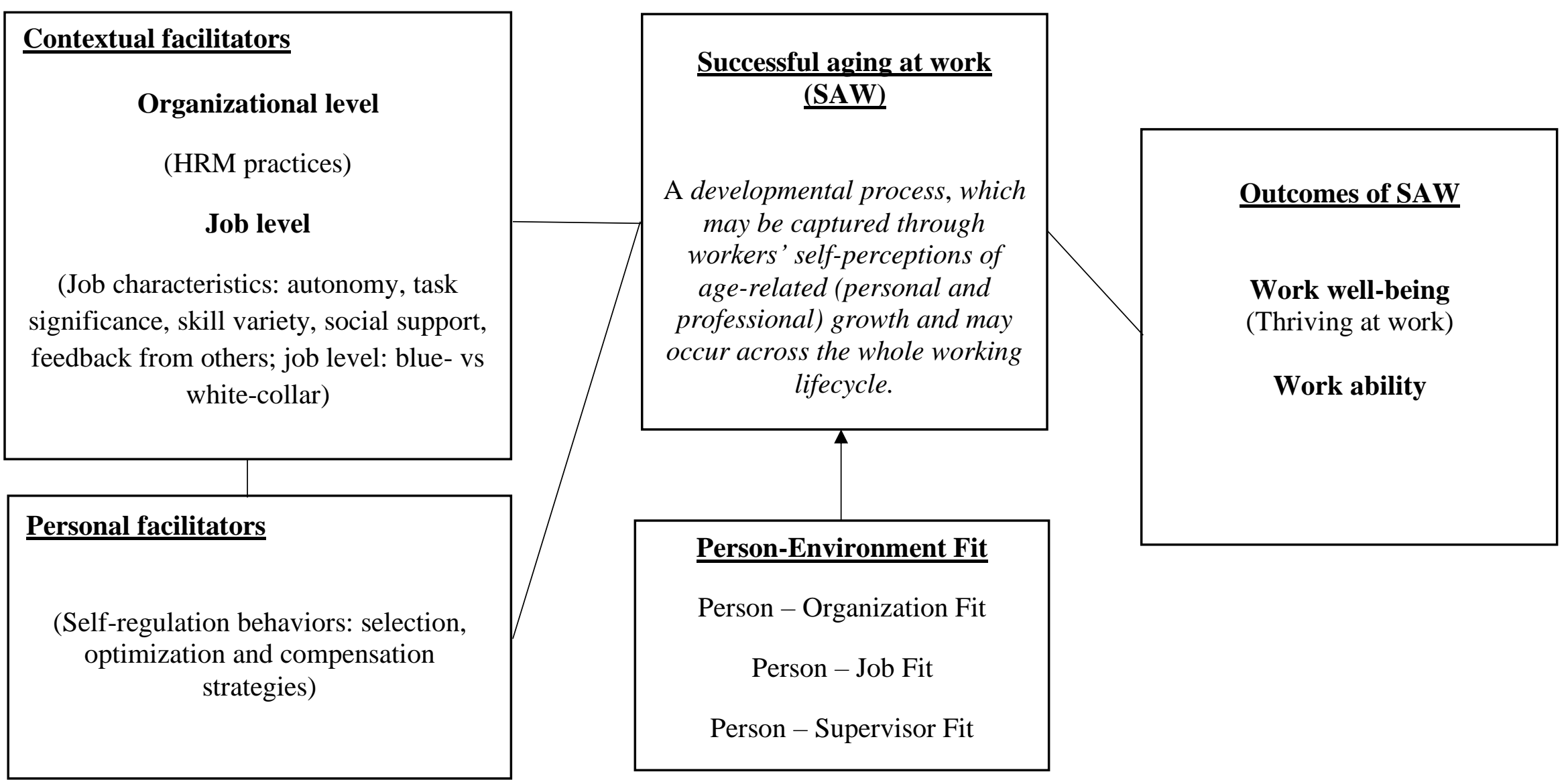

Figure 1: Significant relationships between SAW and other constructs. 